\title{
Effect of repaglinide on cloned beta cell, cardiac and smooth muscle types of ATP-sensitive potassium channels
}

\author{
M.Dabrowski ${ }^{1}$, P.Wahl ${ }^{2}$, W.E.Holmes ${ }^{3}$, F.M.Ashcroft ${ }^{1}$ \\ ${ }^{1}$ University Laboratory of Physiology, Oxford, UK \\ ${ }^{2}$ Department of Molecular Pharmacology, Novo Nordisk, 2760 Maaloev, Denmark \\ ${ }^{3}$ Millennium Pharmaceuticals, Cambridge, Massachusetts, USA
}

\section{Abstract}

Aims/hypothesis. The carbamoylbenzoic acid derivative repaglinide is a potent short-acting insulin secretagogue that acts by closing ATP-sensitive potassium $\left(\mathrm{K}_{\mathrm{ATP}}\right)$ channels in the plasma membrane of the pancreatic beta cell. In this paper we investigated the specificity of repaglinide for three types of cloned $\left(\mathrm{K}_{\mathrm{ATP}}\right)$ channel composed of the inwardly rectifying potassium channel Kir6.2 and either the sulphonylurea receptor SUR1, SUR2A or SUR2B, corresponding to the beta cell, cardiac and either smooth muscle types of $\mathrm{K}_{\mathrm{ATP}}$ channel, respectively.

Methods. The action of the drug was studied by whole-cell current recordings of $\mathrm{K}_{\text {АTP }}$ channels expressed either in Xenopus oocytes or mammalian cells (HEK293). We also used inside-out macropatches excised from Xenopus oocytes for detailed analysis of repaglinide action.

Results. The drug blocked all three types of $\mathrm{K}_{\mathrm{ATP}}$ channel with similar potency, by interacting with a low-affinity site on the pore-forming subunit of the channel (Kir6.2: half-maximal inhibition $230 \mu \mathrm{mol} / \mathrm{l})$ and with a high-affinity site on the regulatory subunit, the sulphonylurea receptor (SUR: halfmaximal inhibition 2-8 nmol/l). There was no difference in potency between channels containing SUR1, SUR2A or SUR2B. MgADP potentiated the inhibitory effect of repaglinide on Kir6.2/SUR1 and (to a lesser extent) Kir6.2/SUR2B, but not on Kir6.2/ SUR2A.

Conclusion/interpretation. Repaglinide interacts with a site common to all three types of sulphonylurea receptor leading to inhibition of the $\mathrm{K}_{\text {ATP }}$ channel. The fact that $\mathrm{MgADP}$ potentiated this effect in the case of the beta cell, but not cardiac, type of channel could help explain why the drug shows no adverse cardiovascular side-effects in vivo. [Diabetologia (2001) 44: 747-756]

Keywords Repaglinide, ATP-sensitive $\mathrm{K}^{+}$-channel, inwardly rectifying potassium channel, sulphonylurea receptor
The ATP-sensitive potassium $\left(\mathrm{K}_{\mathrm{ATP}}\right)$ channels are a family of potassium channels that are inhibited by ATP and activated by MgADP. They thereby couple

Received: 13 December 2000 and in revised form: 14 February 2001

Corresponding author: Prof. Frances M Ashcroft, University Laboratory of Physiology, Parks Road, Oxford OX1 3PT, UK Abbreviations: $\mathrm{K}_{\mathrm{ATP}}$ channel, ATP-sensitive potassium channel; SUR, sulphonylurea receptor; PCO, potassium channel opener; Kir, inwardly rectifying $\mathrm{K}^{+}$channel; TEVC, two electrode voltage clamp; HEK293 cell, Human Embryo Kidney 293 cell. cell metabolism to the electrical activity of the cell membrane. They are widely expressed in muscle, neural and endocrine tissues, where they play important physiological roles. In pancreatic beta cells they couple changes in blood glucose concentration to insulin secretion [1], in cardiac muscle they are involved in action potential shortening during ischaemia [2], in vascular smooth muscle they regulate vessel tone [3], and in skeletal muscle they contribute to the enhanced $\mathrm{K}^{+}$efflux and fatigue found during severe exercise [4]. Their physiological role in neurones is not clearly established but it is believed that they modulate synaptic transmitter release [5] 
and contribute to the response to cerebral ischaemia [6].

The metabolic regulation of $\mathrm{K}_{\mathrm{ATP}}$ channel activity is not fully understood, although it seems clear that adenine nucleotides play a key role. ATP blocks the channel by binding directly to the protein; ATP hydrolysis is not required because inhibition is $\mathrm{Mg}^{2+}$ independent and is mimicked by nonhydrolysable ATP analogues [1]. In contrast, Mg-nucleotides stimulate channel activity in the absence of ATP and antagonize the inhibitory effects of ATP. It is therefore currently believed that both ATP and MgADP determine the basal activity of $\mathrm{K}_{\mathrm{ATP}}$ channels and that changes in $\mathrm{K}_{\mathrm{ATP}}$ channel activity are produced by metabolically-generated variations in the intracellular concentrations of these nucleotides.

$\mathrm{K}_{\text {ATP }}$ channels are inhibited with high affinity by sulphonylurea drugs, like tolbutamide and glibenclamide, that are used clinically to treat Type II (non insulin-dependent) diabetes mellitus, and by a large group of non-sulphonylurea drugs, many of which are benzoic acid derivatives [7]. They are also activated by a chemically diverse group of compounds known as potassium channel openers (PCOs). These $\mathrm{K}_{\mathrm{ATP}}$ activators and inhibitors show a variable tissue specificity, reflecting the different expression levels and molecular composition of $\mathrm{K}_{\mathrm{ATP}}$ channels in these tissues.

$\mathrm{K}_{\text {ATP }}$ channels are composed of two different types of protein subunits: an inwardly rectifying potassium channel (Kir6.x) and a sulphonylurea receptor (SUR) [8-10]. The latter is named for its ability to bind sulphonylureas with high affinity and is a member of the ATP-binding cassette transporter (ABC) superfamily. The $\mathrm{K}_{\mathrm{ATP}}$ channel is an octamer, assembled from four SUR subunits and four Kir6.x subunits [11-13]. There is evidence that Kir6.2 serves as the pore of the $\mathrm{K}_{\mathrm{ATP}}$ channel in beta cells, heart, skeletal muscle and some types of smooth muscle $[9,10]$. The sulphonylurea receptor subunit varies, however, being SUR1 in beta cells, SUR2A in cardiac and skeletal muscle and SUR2B in smooth muscle [8, 14-16]. SUR1 and SUR2 are the products of different genes and show $70 \%$ identity. SUR2 is differentially spliced and SUR2A and SUR2B, the two splice variants most commonly studied, differ only in their last forty-two amino acids.

A combination of molecular biological and electrophysiological studies has revealed that Kir6.2 forms the channel pore and contains the inhibitory binding site for ATP, whereas SUR acts as a regulatory subunit conferring sensitivity to Mg-nucleotides, PCOs, sulphonylureas and some non-sulphonylurea compounds (for review, see [17]). The different types of cloned $\mathrm{K}_{\text {ATP }}$ channel exhibit different drug specificities, which are endowed by their different SUR subunits. Thus gliclazide and tolbutamide inhibit Kir6.2/SUR1 (beta cell type) but not Kir6.2/SUR2A (cardiac type)
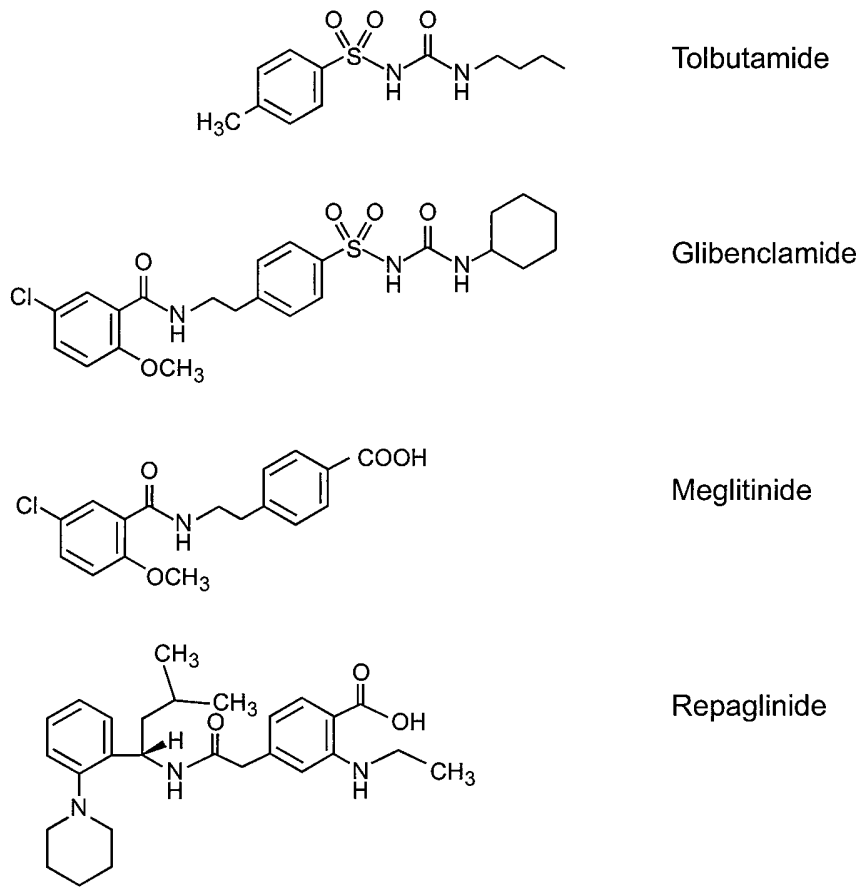

Repaglinide

Fig. 1. Molecular structures of tolbutamide, glibenclamide, meglitinide and repaglinide

or Kir6.2/SUR2B (smooth muscle type) channels with high potency, while glibenclamide and the benzoic acid derivative meglitinide block all three types of channel with similar potency $[18,19]$.

Repaglinide is a carbamoylbenzoic acid derivative that has been shown to be effective in blocking beta cell $\mathrm{K}_{\text {ATP }}$ channels and in stimulating insulin release from islets and isolated perfused pancreas [20, 21]. It also enhances insulin secretion in Type II diabetic patients and hereditarily diabetic rats $[22,23]$. Figure 1 compares the structure of repaglinide with that of the sulphonylureas tolbutamide and glibenclamide, and with the benzoic acid derivative meglitinide. Computer-based molecular modelling studies have shown that repaglinide and glibenclamide differ in structure from meglitinide $[24,25]$. In this paper, we investigated the effect of repaglinide on cloned $\mathrm{K}_{\mathrm{ATP}}$ channels composed of Kir6.2 and either SUR1 (beta cell type), SUR2A (cardiac/skeletal muscle type) or SUR2B (smooth muscle type), heterologously expressed in Xenopus oocytes or HEK293 cells.

\section{Materials and methods}

Molecular biology. For excised patch studies, mouse Kir6.2 (Genbank D50581, [9, 10]), rat SUR1 (Genbank L40624, [8]), SUR2A (Genbank D83598, [14]) and SUR2B (Genbank D86038, [16]) cDNAs were cloned in the pBF vector. A truncated form of Kir6.2 (Kir6.2 $\Delta \mathrm{C} 36$ ), which lacks the C-terminal 36 amino acids and forms functional channels in the absence of SUR, was prepared as described previously [26]. Experiments on intact oocytes were carried out using human clones of 
Kir6.2 (Genbank D50582), SUR2A (Genbank AF061323, [27]) and SUR2B (Genbank AF061324, [27]) and rat SUR1 as above. The human clones differ by less than $4 \%$ in amino acid sequence from their rodent counterparts.

Capped mRNA was prepared using the mMESSAGE mMACHINE large scale in vitro transcription kit (Ambion, Austin, Tex., USA) or the mRNA capping kit (Stratagene, La Jolla, Calif., USA), as previously described [28].

Oocyte collection. Females of the African clawed frog Xenopus laevis were anaesthetised with MS222 ( $2 \mathrm{~g} / \mathrm{l}$ added to the water). One ovary was removed via a mini-laparotomy, the incision sutured and the animal allowed to recover. Once the wound had completely healed, the second ovary was removed in a similar operation and the animal was then killed by decapitation whilst under anaesthesia. Animal experiments were conducted in accordance with UK Home Office Regulations and with local ethical approval. Immature stage V-VI oocytes were incubated for $60 \mathrm{~min}$ with $1.0 \mathrm{mg} / \mathrm{ml}$ collagenase (Sigma, type V) and manually defolliculated. Oocytes were either injected with approximately $1 \mathrm{ng}$ Kir6.2 $\triangle \mathrm{C} 36 \mathrm{mRNA}$ or coinjected with approximately $0.1 \mathrm{ng}$ Kir6.2 mRNA and approximately $2 \mathrm{ng}$ of mRNA encoding one of the types of SUR. The final injection volume was $50 \mathrm{nl} /$ oocyte. Isolated oocytes were maintained in Barth's solution and studied 1-7 days after injection [28].

Electrophysiology - two electrode voltage clamp (TEVC). Whole-cell currents were measured using a two-electrode voltage-clamp amplifier (Warner OC725) and in-house software at $20-24^{\circ} \mathrm{C}$ [29]. Currents were filtered at $0.1 \mathrm{kHz}$ and digitized at $0.24 \mathrm{kHz}$. TEVC electrodes were pulled from thin-walled borosilicate glass and had resistances between 0.4 and $1 \mathrm{M} \Omega$ when filled with $3 \mathrm{~mol} / \mathrm{l} \mathrm{KCl}$. $\mathrm{K}_{\mathrm{ATP}}$ currents were activated by metabolic inhibition with $3 \mathrm{mmol} / \mathrm{l}$ azide and currents were recorded in extracellular solution containing (mmol/1): $\mathrm{KCl} 90$, $\mathrm{MgCl}_{2} 2.5$, HEPES 10 (pH 7.2 with $\mathrm{KOH}$ ). The holding potential was set to the zero current potential $(-10$ or $-20 \mathrm{mV})$. Hyperpolarizations of 10 or $20 \mathrm{mV}$ amplitude and $3 \mathrm{~s}$ duration were applied every $30 \mathrm{~s}$. Repaglinide (chemical name (S)-(+)2-ethoxy-4[2-[[3-methyl-1-[2-(1-piperidinyl)-phenyl]-butyl] amino]-2-oxo-ethyl] benzoic acid) was prepared as a $50 \mathrm{mmol} / 1$ stock solution in DMSO. In control experiments, DMSO at the maximum concentration applied $(2 \%)$ was without effect on the $\mathrm{K}_{\mathrm{ATP}}$ current. Concentration-response curves were obtained by adding increasing amounts of repaglinide to the azide solution (because the effect of the drug was irreversible on the time scale of the experiments).

Electrophysiology - mammalian cells. Currents from HEK293 cells stably expressing human (hu) SUR1 and huKir6.2 were recorded and digitized using an EPC9 patch-clamp amplifier (List Electronik, Darmstadt, Germany) and Pulse + PulseFit v.8.07 Software (HEKA Elektronik, Lambrecht/Pfalz, Germany) on a Macintosh Quadra computer. Cells were dialyzed with intracellular solution containing (in mmol/l): $\mathrm{KCl} 120, \mathrm{CaCl}_{2} 2, \mathrm{MgCl}_{2} 1$, HEPES 20, EGTA 5 and $\mathrm{K}_{2}$ ATP 0.3 (pH 7.3 with $\mathrm{KOH}$ ). The bath solution contained (in mmol/l): $\mathrm{NaCl} 140, \mathrm{KCl} 5, \mathrm{CaCl}_{2} 1.8$, $\mathrm{MgCl}_{2}$, HEPES 10 and mannitol 20 (pH 7.4 with $\mathrm{NaOH}$ ). The cells were clamped at $-70 \mathrm{mV}$ and currents were evoked by repetitive $250 \mathrm{~ms}, 10 \mathrm{mV}$ depolarizing voltage steps. Increasing concentrations of repaglinide were applied by a gravity-driven perfusion system placed $<75 \mu \mathrm{m}$ from the clamped cell.

Electrophysiology - macropatches. Patch pipettes were pulled from thick-walled borosilicate glass and had resistances of $250-500 \mathrm{k} \Omega$ when filled with pipette solution. Macroscopic currents were recorded from giant excised inside-out patches at a holding potential of $0 \mathrm{mV}$ and at $20-24^{\circ} \mathrm{C}$ [30]. Currents were evoked by repetitive $3 \mathrm{~s}$ voltage ramps from $-110 \mathrm{mV}$ to $+100 \mathrm{mV}$ and recorded using an EPC7 patch-clamp amplifier (List Electronik, Darmstadt, Germany). They were filtered at $0.2 \mathrm{kHz}$, digitized at $0.4 \mathrm{kHz}$ using a Digidata 1200 Interface and analysed using pClamp software (Axon Instruments, Foster City, Calif., USA).

The pipette (external) solution contained (mmol/l): 140 $\mathrm{KCl}, 1.2 \mathrm{MgCl}_{2}, 2.6 \mathrm{CaCl}_{2}, 10 \operatorname{HEPES}(\mathrm{pH} 7.4$ with $\mathrm{KOH})$. The intracellular (bath) solution contained (mmol/l): $110 \mathrm{KCl}$, $1.4 \mathrm{MgCl}_{2}, 10$ EGTA, 10 HEPES ( $\mathrm{pH} 7.2$ with $\mathrm{KOH}$; final $\left[\mathrm{K}^{+}\right]$: $140 \mathrm{mmol} / \mathrm{l}$ ). Rapid exchange of solutions was achieved by positioning the patch in the mouth of one of a series of adjacent inflow pipes placed in the bath.

The slope conductance was measured by fitting a straight line to the current-voltage relation between $-20 \mathrm{mV}$ and $-100 \mathrm{mV}$ : the average of 5 consecutive ramps was calculated in each solution.

Data Analysis. Concentration-response curves were fitted to the following equation [30]:

$\frac{G}{G_{C}}=x \cdot y$

equation 1

where $G$ is the conductance in the presence of repaglinide, $G_{c}$ is the conductance in control solution, $x$ is a term describing the high affinity site and $y$ is a term describing the low affinity site.

$$
\begin{aligned}
& x=L+\frac{(1-L)}{\left(1+\left([\text { Repaglinide }] / I C_{50(1)}\right)^{h 1}\right)} \\
& y=\frac{1}{\left(1+\left([\text { Repaglinide }] / I C_{50(2)}\right)^{h 2}\right)}
\end{aligned}
$$

equation 2

equation 3

where [Repaglinide] is the repaglinide concentration, $I C_{50(1)}$, $I C_{50(2)}$ are the repaglinide concentrations at which inhibition is half maximal at high and low-affinity sites, respectively; $h 1, h 2$ are the Hill coefficients (slope factors) for the high and low-affinity sites, respectively; and $\mathrm{L}$ is the fractional conductance remaining when the high-affinity sites are maximally occupied. When only a single site is present, the equation reduces to:

$G / G_{c}=x$

equation 4

Data were fitted using Microcal Origin software (Microcal Software, Northhampton, Mass., USA).

Concentration-response curves were constructed by expressing the conductance in the presence of repaglinide as a fraction of the mean of the conductance measured in control solution before addition of the drug. In some excised patches $(\sim 10 \%), \mathrm{K}_{\mathrm{ATP}}$ currents ran down rapidly with time in a linear fashion. To control for this rundown, a straight line was fitted to the decay of the slope conductance in control solution and extrapolated to the same time point at which the slope conductance in the presence of the drug was measured. This value was then taken as the control slope conductance level. Data are presented as means \pm 1 standard error of the mean. Significance was tested by Student's $t$-test. A $p$ value of less than 0.05 was considered to be statistically significant.

\section{Results}

Whole cell experiments. We first examined the block of Kir6.2/SUR1, Kir6.2/SUR2A and Kir6.2/SUR2B 
Kir6.2/SUR1
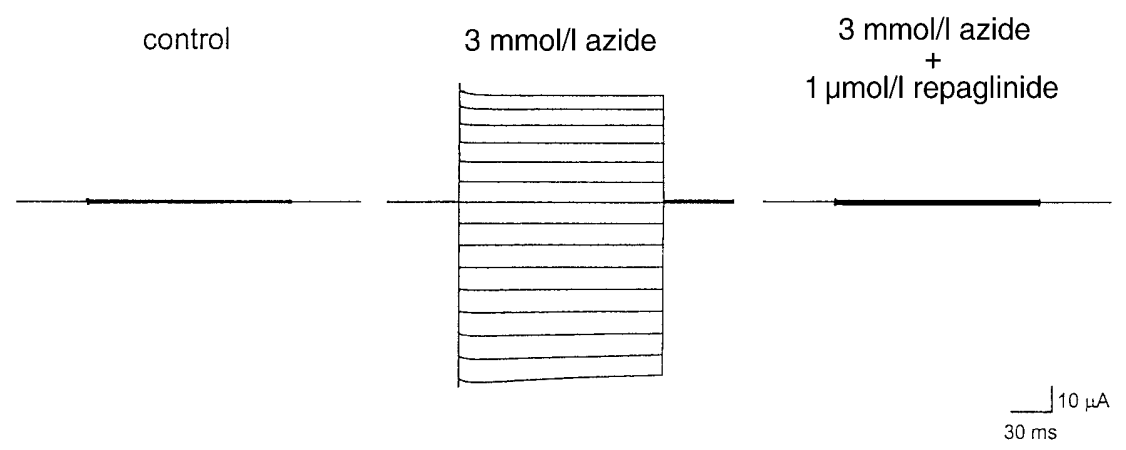

Kir6.2/SUR2A
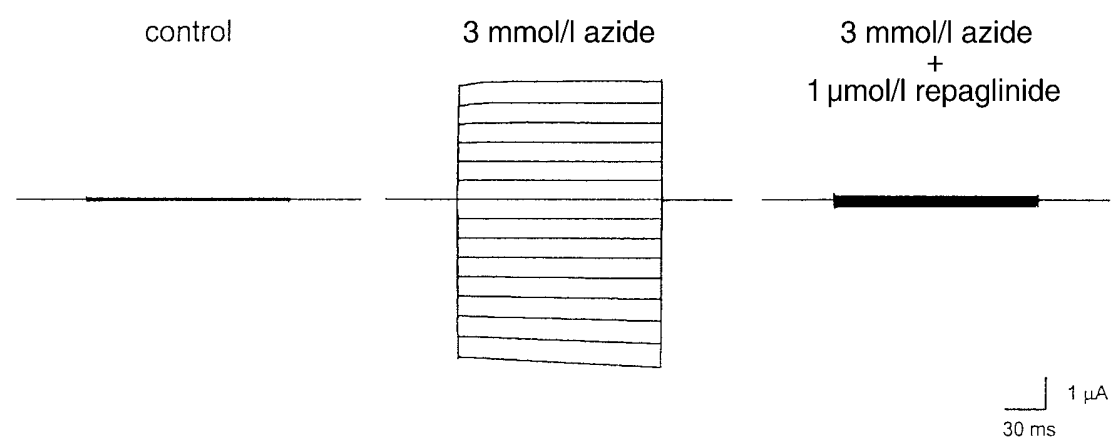

Kir6.2/SUR2B
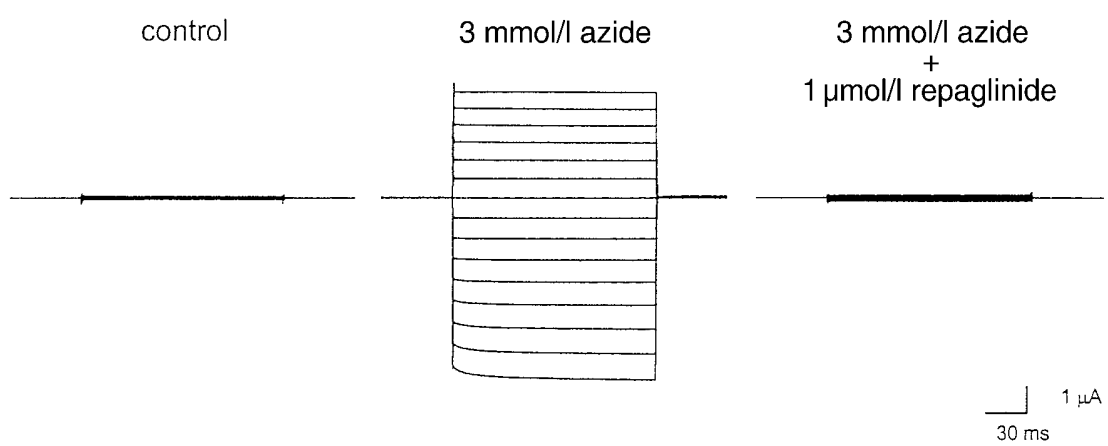

Fig. 2. Effect of repaglinide on Kir6.2/SUR1, Kir6.2/SUR2A and Kir6.2/SUR2B currents in intact oocytes. Membrane currents recorded in the absence or presence of $3 \mathrm{mmol} / \mathrm{l}$ azide, or in the presence of $3 \mathrm{mmol} / \mathrm{l}$ azide plus $1 \mu \mathrm{mol} / \mathrm{l}$ repaglinide in response to a series of voltage steps from $-90 \mathrm{mV}$ to $+50 \mathrm{mV}$ from intact oocytes coexpressing Kir6.2 and either SUR1, SUR2A or SUR2B. Note that the scale on the y axis differs in the upper panel and the two lower panels

currents by repaglinide in intact oocytes, using a twoelectrode voltage clamp. As previously described [28, 30], only very small currents were recorded from oocytes expressing Kir6.2/SUR1, Kir6.2/SUR2A or Kir6.2/SUR2B in control solution. These had amplitudes similar to those found in water-injected oocytes. This results from inhibition of $\mathrm{K}_{\mathrm{ATP}}$ channels by cytoplasmic ATP. We therefore activated $\mathrm{K}_{\mathrm{ATP}}$ channels by metabolic inhibition with $3 \mathrm{mmol} / \mathrm{l}$ azide.
As shown in Figure 2, metabolic poisoning induced a very large current increase in oocytes expressing Kir6.2/SUR1 and smaller currents in oocytes coinjected with Kir6.2 and either SUR2A or SUR2B. Mean current amplitudes in $3 \mathrm{mmol} / \mathrm{l}$ azide were $698 \pm 70 \mathrm{nA} / \mathrm{mV}(n=6), 20.9 \pm 6.5 \mathrm{nA} / \mathrm{mV}(n=6)$ and $23.6 \pm 4.3 \mathrm{nA} / \mathrm{mV}(n=6)$ for oocytes expressing Kir6.2/SUR1, Kir6.2/SUR2A or Kir6.2/SUR2B, respectively, compared to $<2 \mathrm{nA} / \mathrm{mV}$ in control oocytes. Current activation by azide probably involves primarily the action of the drug on mitochondrial metabolism, because when tested in excised patches $3 \mathrm{mmol} / \mathrm{l}$ azide actually causes a small inhibition of recombinant $\mathrm{K}_{\mathrm{ATP}}$ channels [31].

Repaglinide was tested once the current had reached a stable level of activation. This was normally about $10 \mathrm{~min}$ after exposure to the azide solution for Kir6.2/SUR1 currents and after $20 \mathrm{~min}$ for Kir6.2/SUR2A and Kir6.2/SUR2B currents. At a 


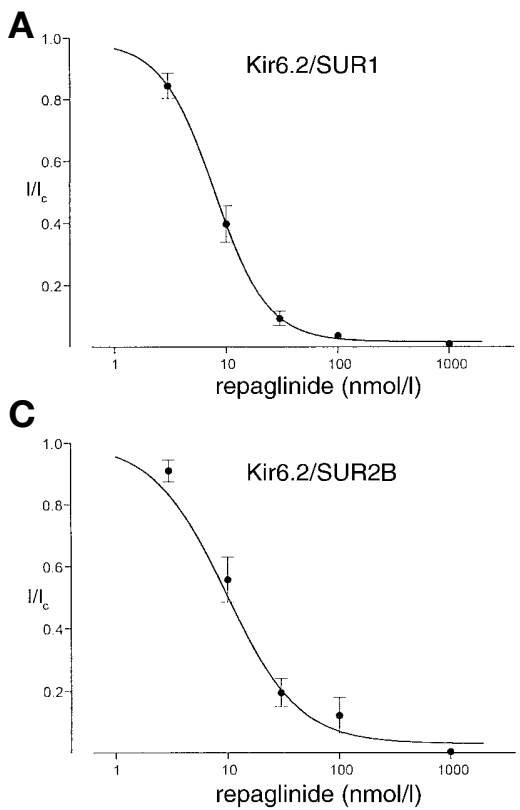

Fig.3A-C. Effect of repaglinide on Kir6.2/SUR1, Kir6.2/ SUR2A and Kir6.2/SUR2B currents in intact oocytes. Repaglinide concentration-response relationships for (A) Kir6.2/ SUR1, (B) Kir6.2/SUR2 or (C) Kir6.2/SUR2B currents measured in intact oocytes using a two-electrode voltage clamp. The macroscopic current at $-30 \mathrm{mV}$ in the presence of repaglinide (I) is expressed as a fraction of its mean amplitude in the absence of the drug $\left(\mathrm{I}_{\mathrm{C}}\right)$. The symbols represent the mean, and the vertical bars indicate 1 SEM. Data were fit to a single-site model (eqn 4). For Kir6.2/SUR1, $I C_{50}=7.4 \mathrm{nmol} / \mathrm{l}$, $h 1=1.9(n=6) ;$ Kir6.2/SUR2A, $I C_{50}=8.7 \mathrm{nmol} / 1, h 1=2.1$ $(n=5)$; Kir6.2/SUR2B, $I C_{50}=10.2 \mathrm{nmol} / 1, h 1=1.9(n=5)$

concentration of $1 \mu \mathrm{mol} / 1$, the drug completely inhibited all three types of channel (Fig.2). The effect of repaglinide was slow in onset taking $10-15 \mathrm{~min}$ to reach a steady state level at the lower concentrations, and was not reversed within $10 \mathrm{~min}$ after return to control solution (containing $3 \mathrm{mmol} / \mathrm{l}$ azide). These results are in agreement with earlier experiments on insulin-secreting betaTC3 cells [20].

The relationship between repaglinide concentration and channel inhibition is given in Figure 3. Repaglinide blocked Kir6.2/SUR1 currents by interaction with a site that had an $\mathrm{IC}_{50}$ of $7.4 \pm 1.2 \mathrm{nmol} / \mathrm{l}$ $(n=6)$ and a Hill coefficient of $1.94 \pm 0.35(n=6)$. The drug also blocked Kir6.2/SUR2A and Kir6.2/ SUR2B currents with similar affinity $\left(\mathrm{IC}_{50}, 8.7 \pm 1.5\right.$ $\mathrm{nmol} / \mathrm{l}, n=5$, and $10.2 \pm 1.6 \mathrm{nmol} / \mathrm{l}, n=5$, respectively). The Hill coefficients were $2.07 \pm 0.39(n=5)$ and $1.88 \pm 0.22(n=5)$ for Kir6.2/SUR2A and Kir6.2/ SUR2B currents, respectively. In all cases, the residual currents (not blocked by repaglinide) were very small and similar to those found before addition of azide: $1.0 \pm 0.5 \% \quad(n=6) ; 2.6 \pm 1.9 \% \quad(n=5)$ and $0.3 \pm 0.2 \%(n=5)$ for Kir6.2/SUR1, Kir6.2/SUR2A and Kir6.2/SUR2B, respectively.

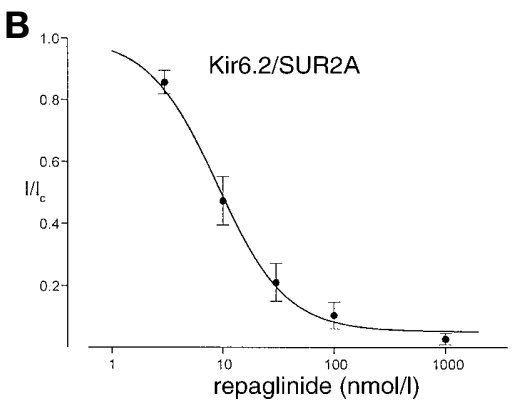

The potency of repaglinide on the human beta cell $\mathrm{K}_{\text {ATP }}$ channel was assessed using human embryonic kidney cells (HEK293) stably expressing human Kir6.2 and human SUR1. The whole-cell current density induced by intracellular dialysis with a solution containing a low ATP concentration $(0.3 \mathrm{mmol} / \mathrm{l})$ was $8520 \pm 860 \mathrm{pS} / \mathrm{pF}(n=12)$. This current could be completely blocked by $1 \mu \mathrm{mol} / \mathrm{l}$ repaglinide with an $\mathrm{IC}_{50}$ of $8 \pm 4 \mathrm{nmol} / \mathrm{l}(n=9)$ (data not shown).

Excised patch experiments. We next recorded macroscopic currents in inside-out membrane patches from Xenopus oocytes coexpressing Kir6.2 and either SUR1, SUR2A or SUR2B. In all cases, the currents were very small in the cell-attached configuration but increased dramatically when the patch was excised into nucleotide-free solution, consistent with the idea that the $\mathrm{K}_{\mathrm{ATP}}$ channel is blocked in the intact oocyte by cytoplasmic nucleotides such as ATP.

Figure 4 shows that application of $1 \mu \mathrm{mol} / 1 \mathrm{repagli-}$ nide to the intracellular membrane surface blocked Kir6.2/SUR1, Kir6.2/SUR2A and Kir6.2/SUR2B currents. The mean inhibition produced by the drug was $50 \pm 4 \% \quad(n=5), 38 \pm 5 \% \quad(n=20)$, and $49 \pm 4 \%$ $(n=12)$, respectively. In contrast to experiments on intact oocytes, repaglinide inhibited the currents rapidly (within seconds) when applied to the intracellular side of the membrane. There was no significant recovery of the current upon removal of the drug.

The relationship between repaglinide concentration and channel inhibition is given in Figure 5. As is observed for the inhibition of Kir6.2/SUR1 currents by sulphonylureas $[18,30]$, repaglinide inhibits all three types of channel by interaction with both highaffinity and low-affinity sites. There was no significant difference between the $\mathrm{IC}_{50}$ and Hill coefficients for the different high-affinity sites. The $\mathrm{IC}_{50}$ was 
Kir6.2/SUR1

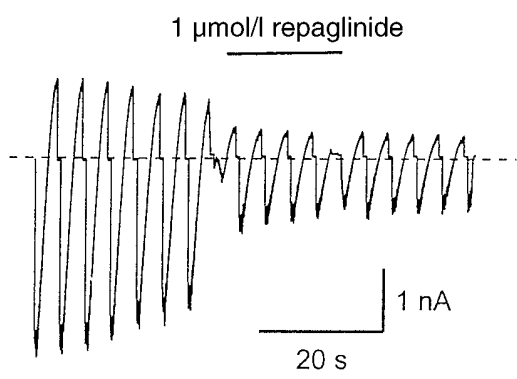

Kir6.2/SUR2B

$1 \mu \mathrm{mol} / \mathrm{l}$ repaglinide

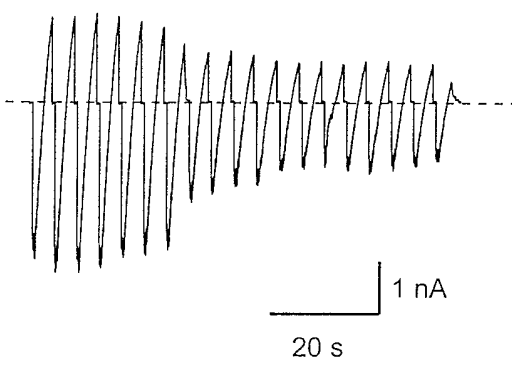

Fig.4. Effect of repaglinide on Kir6.2/SUR1, Kir6.2/SUR2A, Kir6.2/SUR2B or Kir6.2 $\Delta$ C36 currents in inside-out patches. Macroscopic currents recorded from inside-out patches in response to a series of voltage ramps from $-110 \mathrm{mV}$ to $+100 \mathrm{mV}$ from oocytes coexpressing Kir6.2 and either SUR1, SUR2A or SUR2B; or expressing Kir6.2AC36. Repaglinide was added as indicated by the bars

$5.6 \pm 2 \mathrm{nmol} / \mathrm{l}(n=5), 2.2 \pm 0.4 \mathrm{nmol} / 1 \quad(n=5)$ and $2.0 \pm 1 \mathrm{nmol} / \mathrm{l}(n=8)$ for channels containing SUR1, SUR2A and SUR2B respectively. These values are similar to those obtained for inhibition of whole cell currents in intact oocytes. The Hill coefficients were all close to unity, in contrast to the results of wholecell studies.

Interaction of repaglinide with the high-affinity site did not produce complete inhibition of the $\mathrm{K}_{\mathrm{ATP}}$ current but instead blocked the current by about $50 \%$. Similar results have been observed for the sulphonylureas tolbutamide and glibenclamide [18]. High affinity repaglinide block saturated at around $100 \mathrm{nmol} / \mathrm{l}$ and the extent of steady state block was $61 \pm 7 \% \quad(n=5), \quad 51 \pm 3 \% \quad(n=5) \quad$ and $54 \pm 1 \%$ $(n=8)$ for Kir6.2/SUR1, Kir6.2/SUR2A, and Kir6.2/ SUR2B respectively.

It was more difficult to measure the $\mathrm{IC}_{50}$ for the low-affinity site accurately, because repaglinide was relatively insoluble at high concentrations, and because the patch was less stable at repaglinide concentrations above $300 \mu \mathrm{mol} / \mathrm{l}$. Fitting a two-site model to the data, however, gave $\mathrm{IC}_{50}$ values of $23 \pm 12 \mu \mathrm{mol} / 1$ $(n=5), 27 \pm 6 \mu \mathrm{mol} / 1 \quad(n=5)$ and $212 \pm 18 \mu \mathrm{mol} / 1$
Kir6.2/SUR2A

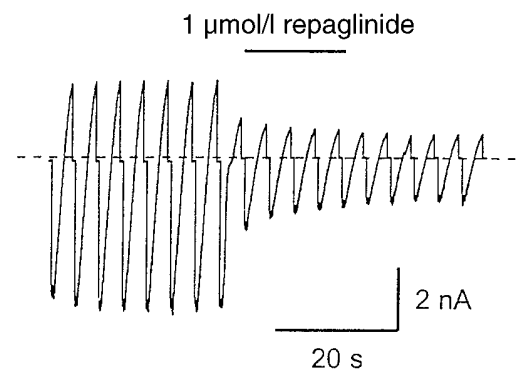

Kir6.2 $\triangle \mathrm{C} 36$

$300 \mu \mathrm{mol} / \mathrm{l}$ repaglinide

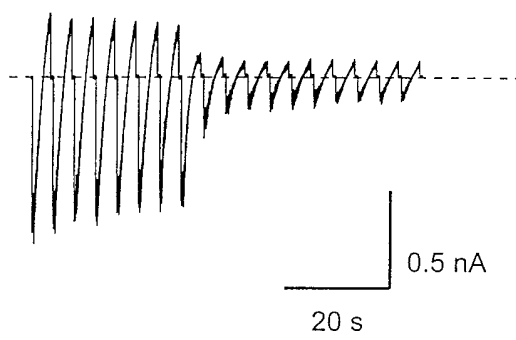

$(n=8)$ for Kir6.2/SUR1, Kir6.2/SUR2A and Kir6.2/ SUR2B respectively.

Sulphonylureas such as glibenclamide and tolbutamide mediate low-affinity inhibition of Kir6.2/SUR1, Kir6.2/SUR2A and Kir6.2/SUR2B channels by interaction with a site located on the Kir6.2 subunit [18, 30]. To investigate whether this is also the case for repaglinide, we tested the effect of the drug on a Cterminally truncated form of Kir6.2 (Kir6.2 $\Delta$ C36) lacking the last 36 amino acids, that is capable of expression in the absence of SUR [26]. Repaglinide blocked Kir6.2 $\Delta \mathrm{C} 36$ currents at low affinity (Fig.4, $5)$. Although it was not possible to obtain an accurate $\mathrm{IC}_{50}$ for channel inhibition because of the reasons described earlier, it is clear from Figure 5D that halfmaximal inhibition is produced by about $230 \mu \mathrm{mol} / 1$ repaglinide, suggesting that the low-affinity site for repaglinide resides on Kir6.2. These data also confirm that the high-affinity site for repaglinide lies on the sulphonylurea receptor subunit because high-affinity inhibition was only observed when Kir6.2 was expressed in the presence of SUR.

High-affinity inhibition of Kir6.2/SUR1 currents by tolbutamide is abolished by mutation of the serine residue at position 1238 to threonine (SUR1S1238Y). This mutation also renders the glibenclamide block of Kir6.2/SUR1 rapidly reversible, whereas the effect of the drug on the wild-type channel shows little reversibility on the time-scale (min) of the experiments [32]. We therefore examined the effect of repaglinide on Kir6.2/SUR1-S1238Y currents. Interestingly, this mutation did not affect repaglinide inhibition or its reversibility. In patches excised from 

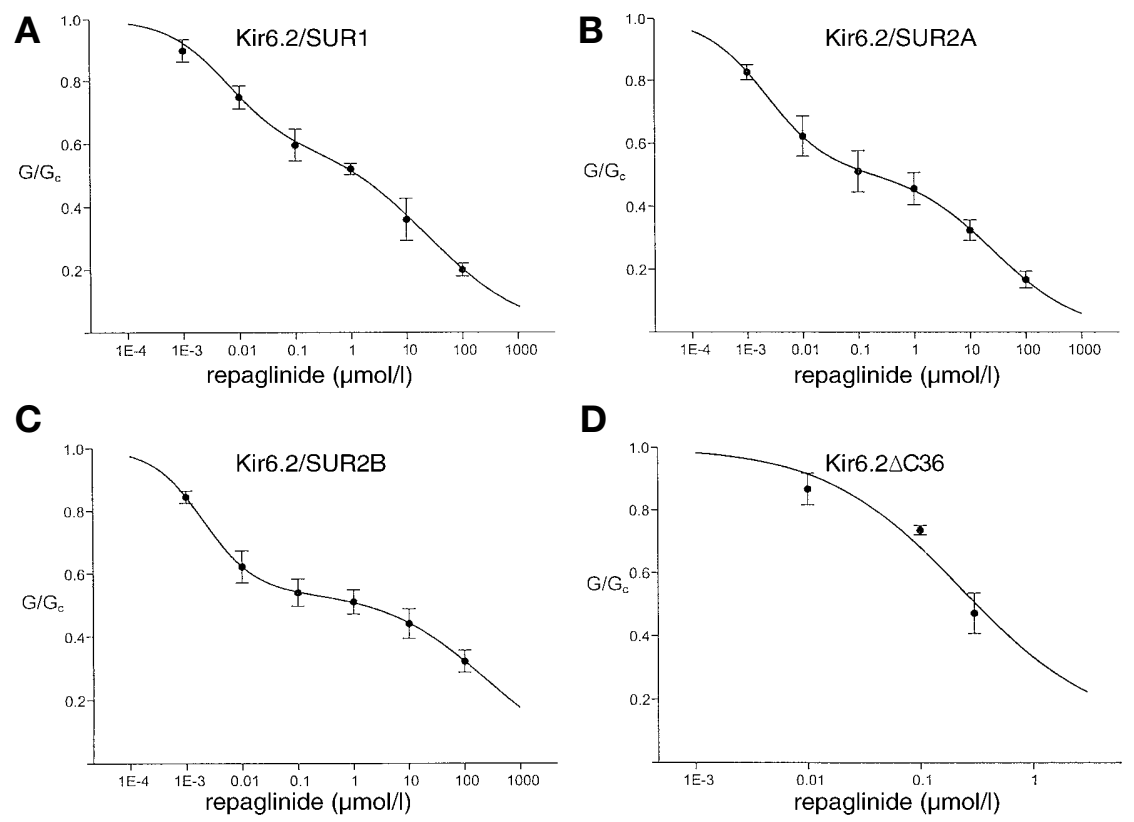

Fig.5A-D. Effect of repaglinide on Kir6.2/SUR1, Kir6.2/ SUR2A, Kir6.2/SUR2B or Kir6.2AC36 currents in inside-out patches. Repaglinide concentration-response relationships for (A) Kir6.2/SUR1, (B) Kir6.2/SUR2A, (C) Kir6.2/SUR2B or (D) Kir6.2 $\Delta \mathrm{C} 36$ currents. The macroscopic conductance in the presence of repaglinide $(\mathrm{G})$ is expressed as a fraction of its mean amplitude in the absence of the drug $\left(\mathrm{G}_{\mathrm{C}}\right)$. The symbols represent the mean, and the vertical bars indicate 1 SEM. Kir6.2 $\Delta$ C36 concentration-response curves were fitted with eqn 4: $I C_{50}=229 \mu \mathrm{mol} / 1, h 1=0.7(n=6)$. All other data were fitted with a two-site model (eqn 1). For Kir6.2/SUR1, $I C_{50(1)}=5.6 \mathrm{nmol} / \mathrm{l}, h 1=0.8, I C_{50(2)}=23 \mu \mathrm{mol} / \mathrm{l}, h 2=0.5, \mathrm{~L}=$ $0.61(n=5)$; for Kir6.2/SUR2A, $I C_{50(1)}=2.2 \mathrm{nmol} / 1, h 1=0.8$, $I C_{50(2)}=27 \mu \mathrm{mol} / \mathrm{l}, h 2=0.6, \mathrm{~L}=0.51(n=5)$; and for Kir6.2/ SUR2B $, \quad I C_{50(1)}=2.0 \mathrm{nmol} / \mathrm{l}, \quad h 1=1.0, \quad I C_{50(2)}=212 \mu \mathrm{mol} / \mathrm{l}$, $h 2=0.5, \mathrm{~L}=0.54(n=8)$. The two-site model (eqn. 1$)$ fits the data shown in $\mathbf{A}, \mathbf{B}$ and $\mathbf{C}$ better than the single-site model (eqn. 4). $P=0.027$ (A), $0.016(\mathbf{B})$ and $0.004(\mathbf{C})$ using F-test (Prism 3.0, Graph Pad software)

oocytes expressing Kir6.2/SUR1-S1238Y $1 \mu \mathrm{mol} / 1$ repaglinide produced a mean inhibition of $45 \pm 8 \%$ $(n=5)$ compared to $50 \pm 4 \%(n=5)$ for wild type SUR1 (data not shown).

Interaction of repaglinide with $M g A D P$. There is a marked discrepancy between the results of our experiments in the intact oocytes, where repaglinide inhibits by interaction with a single high-affinity site, and the results found in inside-out patches, where repaglinide interacts with both high-affinity and low-affinity sites. A similar anomaly is found for sulphonylurea inhibition of beta cell $\mathrm{K}_{\mathrm{ATP}}$ channels, where it has been shown to result from modulation by MgADP $[18,33,34]$. To determine if MgADP also affects repaglinide block of cloned $\mathrm{K}_{\mathrm{ATP}}$ channels, we examined the extent of channel inhibition in the presence and

absence of $100 \mu \mathrm{mol} / \mathrm{l} \mathrm{MgADP}$. Figure 6 shows that $100 \mu \mathrm{mol} / 1$ MgADP potentiated Kir6.2/SUR1, Kir6.2/SUR2A and Kir6.2/SUR2B currents. In addition, repaglinide inhibition of Kir6.2/SUR1 was greatly increased, that of Kir6.2/SUR2B enhanced to a lesser extent and that of Kir6.2/SUR2A was not affected. These results support the view that the greater inhibition observed in intact oocytes could in part be due to the presence of intracellular MgADP, as discussed below.

\section{Discussion}

Our results demonstrate that repaglinide blocks recombinant Kir6.2/SUR1, Kir6/2/SUR2A and Kir6.2/ SUR2B channels, corresponding to the beta cell, cardiac and smooth muscle types of $\mathrm{K}_{\mathrm{ATP}}$ channel, by binding to a site that is located on the SUR subunit. The ability of repaglinide to block all three types of $\mathrm{K}_{\mathrm{ATP}}$ channel with similar affinity suggests that they share a common binding site.

Half-maximal block of Kir6.2/SUR1 channels was observed with $7 \mathrm{nmol} / \mathrm{l}$ repaglinide in intact oocytes and $6 \mathrm{nmol} / \mathrm{l}$ (for the high-affinity site) in excised patches. Because the intact oocyte experiments were carried out using human clones (except for rat SUR1), whereas those on excised patches used the rodent clones (mouse Kir6.2, rat SURs), the data also confirm there is no species difference in repaglinide affinity. Further confirmation is provided by experiments on HEK293 cells expressing human Kir6.2/SUR1 in which repaglinide blocked the whole-cell $\mathrm{K}_{\mathrm{ATP}}$ current half-maximally at a concentration of $8 \mathrm{nmol} / \mathrm{l}$. The $\mathrm{IC}_{50}$ values we report are in good agreement with the $\mathrm{K}_{\mathrm{d}}(\sim 4 \mathrm{nmol} / \mathrm{l})$ of the high-affinity binding site for repaglinide in mouse 


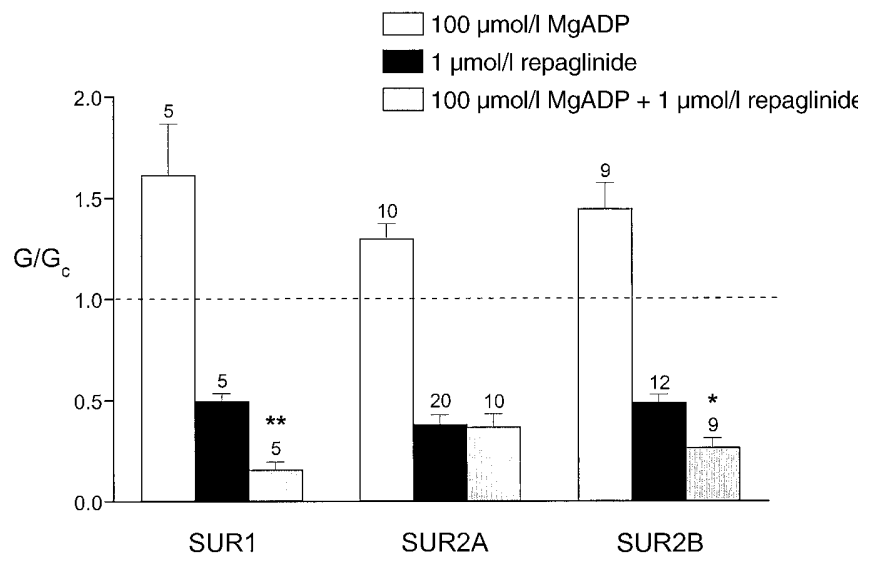

Fig. 6. Effect of MgADP on repaglinide block. Mean amplitude of Kir6.2/SUR1, Kir6.2/SUR2A or Kir6.2/SUR2B conductance, recorded in the presence of $100 \mu \mathrm{mol} / \mathrm{l} \mathrm{MgADP}$, of $1 \mu \mathrm{mol} / \mathrm{l}$ repaglinide or of $100 \mu \mathrm{mol} / \mathrm{l} \mathrm{MgADP}$ plus $1 \mu \mathrm{mol} / \mathrm{l}$ repaglinide, expressed as a percentage of the conductance in control solution (no additions). The dashed line indicates the control level $(100 \%)$. The number of oocytes is given above the bars. ${ }^{*} p<0.002$, ** $p<0.001$ (by Student's $t$-test). The data come from different sets of patches. One set of patches was exposed to control solution, followed first by MgADP solution and then by MgADP plus repaglinide. The other set of patches received control solution followed by repaglinide solution. This procedure was necessitated by the lack of reversibility of repaglinide action

beta cells [35] but are somewhat higher than that found for inhibition of $\mathrm{K}_{\mathrm{ATP}}$ channels in beta cells cultured from neonatal rats $(\sim 90 \mathrm{pmol} / \mathrm{l},[20])$.

The Hill coefficient for repaglinide block was close to two in the intact oocyte but close to unity in the excised patch. A Hill coefficient of one was also reported in repaglinide binding studies [35]. In our view, these results indicate that the binding of a single molecule of repaglinide is sufficient to block the $\mathrm{K}_{\mathrm{ATP}}$ channel but that the steepness of the concentrationresponse relationship is modified by the presence of cytosolic factors. One possibility is that the altered Hill coefficient reflects the loss of the stimulatory effect of MgADP. It is interesting that a Hill coefficient of greater than one (1.8) was found for glibenclamide block of the native beta cell $\mathrm{K}_{\mathrm{ATP}}$ channel in wholecell recordings [36], whereas one of unity was observed in excised patches [18].

Recent studies of cloned channels have revealed that tolbutamide blocks $\mathrm{K}_{\mathrm{ATP}}$ channels containing SUR1, but not SUR2A or SUR2B, subunits [18]. In contrast, meglitinide blocks all three types of cloned $\mathrm{K}_{\mathrm{ATP}}$ channel. This has been interpreted to indicate that sulphonylureas (like tolbutamide) interact with a binding site that is specific to SUR1, whereas benzamido compounds (like meglitinide) interact with a site that is common to all SUR subtypes (for review, see [7]). Glibenclamide, which contains both sulphonylurea and benzamido moieties, is postulated to in- teract with both sites on SUR1 but only a single (benzamido) site on SUR2. The lack of effect on repaglinide inhibition of the SUR1-S1238Y mutation, which abolishes tolbutamide block, argues that the drug does not interact with the sulphonylurea site on SUR1. Rather, the fact that both the rate and potency of repaglinide block is similar for Kir6.2/SUR1, Kir6.2/SUR2A and Kir6.2/SUR2B currents suggests that repaglinide binds to a site that is common to all three types of SUR. Our results do not allow us to conclude whether or not this is the same site as meglitinide or if it is a separate site. However, the ability of repaglinide to displace $\left[{ }^{3} \mathrm{H}\right]$ glibenclamide binding in a competitive manner [35] suggests that if these sites are not identical, they must share a similar structure and they must be allosterically coupled.

Repaglinide blocked recombinant $\mathrm{K}_{\mathrm{ATP}}$ currents rapidly when applied to the intracellular surface of the excised patch. In contrast, inhibition was considerably slower when the drug was applied to the extracellular membrane surface of the intact oocyte, taking many minutes to reach a steady state at low concentrations. There are several possible explanations for this discrepancy. First, the presence of the vitelline membrane surrounding the intact oocyte might slow access of the drug to the extracellular membrane surface. Secondly, cytosolic substances present in the intact cell, but not in the excised patch, could influence the rate of drug binding. Thirdly, the drug binding site might lie on the intracellular side of the membrane. In this case, the slow time course of inhibition observed in intact cells would reflect the uptake of the drug into the cell. There is accumulating evidence that the site at which tolbutamide binds is located on the intracellular side of the membrane $[28,37,38]$ but the binding site for repaglinide is still not known. It has previously been suggested that the binding site for repaglinide could be intracellular [20] and that the slow kinetics of repaglinide block in intact beta cells is strongly influenced by the rate of intracellular uptake and accumulation. Although we favour this idea, we cannot exclude the two other possibilities set out above.

In both excised patches and intact cells, repaglinide block was poorly reversible on the time scale of our experiments. A similar slow off-rate was found in whole-cell recordings of native $\mathrm{K}_{\mathrm{ATP}}$ currents in neonatal rat beta cells: the current was only $80 \%$ of its control value after $250 \mathrm{~min}$ of washing [20]. The slow rate of reversal explains why the ability of repaglinide $(10 \mu \mathrm{mol} / \mathrm{l})$ to inhibit ${ }^{86} \mathrm{Rb}^{+}$efflux from islets persists for at least $20 \mathrm{~min}$ after removal of the drug from the perifusate [39]. The slow off-rate of repaglinide block presumably contributes to the high affinity of the drug. In vivo, repaglinide is classified as a short-acting secretagogue, because its action is rapid in onset and reverses within $2 \mathrm{~h}$ of administration $[22,40,41]$. Glibenclamide takes much longer to re- 
verse, reflecting the different pharmacokinetic profiles of the two drugs. Further, the ability of repaglinide to block Kir6.2/SUR1-S1238Y currents suggests that repaglinide acts by a different mechanism than the sulphonylurea tolbutamide.

It is well known that the inhibitory effects of tolbutamide, glibenclamide, gliclazide and meglitinide on both native beta cell $\mathrm{K}_{\mathrm{ATP}}$ channels and on Kir6.2/SUR1 channels are enhanced in the presence of intracellular MgADP [18, 19, 30, 33, 34]. The enhanced block does not reflect an increased binding affinity for sulphonylureas when $\mathrm{MgADP}$ is present. Instead it results because sulphonylureas abolish the stimulatory action of MgADP mediated by SUR1, whilst leaving the inhibitory effect of the nucleotide on Kir6.2 intact [30]. Inhibition is thus due to the combined blocking actions of MgADP and tolbutamide. Because MgADP is always present in the intact cell but not (unless deliberately added) in excised patches, this effect can account for the increased block observed in intact cells. Our results suggest that a similar effect could operate for repaglinide because the apparent efficacy of this drug is also increased in the presence of MgADP.

In contrast to the beta cell channel, sulphonylurea inhibition of both native and recombinant cardiac $\mathrm{K}_{\text {ATP }}$ channels is decreased (rather than increased) by $\mathrm{MgADP}[30,42]$. This explains why sulphonylureas are less effective in excised patches than in intact cardiac myocytes [42]. The ability of MgADP to increase the apparent efficacy of repaglinide block was not observed for the Kir6.2/SUR2A channels but was observed for $\mathrm{K}_{\mathrm{ATP}}$ channels containing SUR1 and SUR2B. This could be one reason why the potency of the drug is greater on beta cell $\mathrm{K}_{\mathrm{ATP}}$ channels than cardiac $\mathrm{K}_{\mathrm{ATP}}$ channels when measured in vitro [43].

Therapeutic Implications. Our results indicate that in both excised patches and intact cells, repaglinide can interact with cardiac and smooth muscle types of $\mathrm{K}_{\text {ATP }}$ channel, as well as beta cell $\mathrm{K}_{\text {ATP }}$ channels. However, this cross-reactivity does not result in cardiovascular side effects [44, data on file Novo Nordisk A/S]. Likewise, glibenclamide blocks all three types of channel with similar efficacy [18], but the United Kingdom Prospective Diabetes Study found no difference in the mortality, or diabetic endpoints, of patients treated with insulin, glibenclamide or chlorpropamide [45]. There was also no increase in arrhythmia or mortality in patients taking sulphonylureas or insulin in a large Australian study [46]. Although the University Group Diabetes Program reported a significantly increased cardiovascular mortality in patients treated with the sulphonylurea tolbutamide [47], this study was subsequently found to be flawed. The lack of significant cardiovascular effects in patients treated with sulphonylureas could be because cardiac $\mathrm{K}_{\mathrm{ATP}}$ channels are closed under physiological conditions and open only in response to ischaemic stress [2] and because the efficacy of the sulphonylureas on cardiac $\mathrm{K}_{\mathrm{ATP}}$ channels is reduced by MgADP. Furthermore, it is still not clear whether inhibition of the plasma membrane cardiac $\mathrm{K}_{\mathrm{ATP}}$ channel has any adverse effect in vivo.

Acknowledgements. This work was supported by the Wellcome Trust. M.Dabrowski was supported by a grant from ATV. (Denmark). We would like to thank R. Carr for helpful advice.

\section{References}

1. Ashcroft FM, Rorsman P (1989) Electrophysiology of the pancreatic beta-cell. Prog Biophys Mol Biol 54: 87-143

2. Nichols CG, Lederer WJ (1991) Adenosine triphosphatesensitive potassium channels in the cardiovascular system. Am J Physiol 261:H1675-H1686

3. Quayle JM, Nelson MT Standen NB (1997) ATP-sensitive and inwardly rectifying potassium channels in smooth muscle. Physiol Rev 77: 1165-1232

4. Davis NW, Standen NB, Stanfield PR (1991) ATP-dependent potassium channels of muscle cells: their properties, regulation, and possible functions. J Bioenerg Biomembr 23: 509-535

5. Schmid-Antomarchi H, Amoroso S, Fosset M et al. (1990) $\mathrm{K}^{+}$channel openers activate brain sulfonylurea-sensitive $\mathrm{K}^{+}$channels and block neurosecretion. Proc Natl Acad Sci USA 87: 3489-3492

6. Heurteax C, Bertaina V, Widmann C et al. (1993) $\mathrm{K}^{+}$channel openers prevent global ischemia-induced expression of c-fos, c-jun, heat shock protein and amyloid beta-protein precursor genes and neuronal death in rat hippocampus. Proc Natl Acad Sci USA 90: 9431-9435

7. Ashcroft FM, Gribble FM (1999) ATP-sensitive $\mathrm{K}^{+}$channels and insulin secretion: their role in health and disease. Diabetologia 42(8):903-919

8. Aguilar-Bryan L, Nichols CG, Wechsler SW et al. (1995) Cloning of the beta-cell high-affinity sulphonylurea receptor: a regulator of insulin secretion. Science 268: 423-425

9. Inagaki N, Gonoi T, Clement JP 4th et al. (1995) Reconstitution of IKATP: an inward rectifier subunit plus the sulphonylurea receptor. Science 270: 1166-1169

10. Sakura H, Ämmälä C, Smith PA et al. (1995) Cloning and functional expression of the cDNA encoding a novel ATPsensitive potassium channel expressed in pancreatic betacells, brain, heart and skeletal muscle. FEBS Lett. 377: 338-344

11. Clement JP 4th, Kunjilwar K, Gonzalez G et al. (1997) Association and stoichiometry of K(ATP) channel subunits. Neuron 18: 827-838

12. Inagaki N, Gonoi T, Seino S (1997) Subunit stoichiometry of the pancreatic beta-cell ATP-sensitive $\mathrm{K}^{+}$channel. FEBS Lett 409: 232-236

13. Shyng S, Nichols CG (1997) Octameric stochiometry of the KATP channel complex. J Gen Physiol 110: 655-664

14. Inagaki N, Gonoi T, Clement JP et al. (1996) A family of sulfonylurea receptors determines the properties of ATPsensitive $\mathrm{K}^{+}$channels. Neuron 16: 1011-1017

15. Chutkow WA, Simon MC et al. (1996) Cloning, tissue expression, and chromosomal localization of SUR2, the putative drug-binding subunit of cardiac, skeletal muscle, and vascular KATP channels. Diabetes 45: 1439-1445 
16. Isomoto, S, Kondo, C, Yamada M et al. (1996) A novel sulphonylurea receptor forms with BIR (Kir6.2) a smooth muscle type of ATP-sensitive $\mathrm{K}^{+}$channel. J Biol Chem 271: 24321-24325

17. Ashcroft FM, Gribble FM (1998) Correlating structure and function in ATP-sensitive $\mathrm{K}^{+}$channels. Trends Neurosci 21: 288-294

18. Gribble FM, Tucker SJ, Seino S et al. (1998) Tissue specificity of sulphonylureas: studies on cloned cardiac and beta-cell K(ATP) channels. Diabetes 47: 1412-1418

19. Gribble FM, Ashcroft FM (1999) Differential sensitivity of beta-cell and extrapancreatic K(ATP) channels to gliclazide. Diabetologia 42: 845-848

20. Gromada J, Dissing S, Kofod H et al. (1995) Effects of the hypoglycaemic drugs repaglinide and glibenclamide on ATP-sensitive potassium-channels and cytosolic calcium levels in beta TC3 cells and rat pancreatic beta cells. Diabetologia 38: 1025-1032

21. Leclerq-Meyer V, Ladriere L, Fuhlendorff J et al. (1997) Stimulation of insulin and somatostatin release by two meglitinide analogs. Endocrine 7: 311-317

22. Wolfenbuttel BHR, Nijst L, Sels JPJE et al. (1993). Effects of a new oral hypoglycaemic agent, repaglinide, on metabolic control in sulphonylurea-treated patients with NIDDM. Eur J Clin Pharmacol 45: 113-116

23. Ladriére L, Malaisse-Lagae F, Fuhlendorff J et al. (1997) Repaglinide, glibenclamide and glimepride administration to normal and hereditarily diabetic rats. Eur J Pharmacol 335: 227-234

24. Lins L, Brasseur R, Malaisse WJ (1995) Conformational analysis of non-sulfonylurea hypoglycemic agents of the meglitinide family. Biochem Pharmacol 50: 1879-1884

25. Grell W, Hurnaus R, Griss G, Sauter R et al. (1998) Repaglinide and related hypoglycemic benzoic acid derivatives. J Med Chem 41: 5219-5246

26. Tucker SJ, Gribble FM, Zhao C et al. (1997) Truncation of Kir6.2 produces ATP-sensitive K-channels in the absence of the sulphonylurea receptor. Nature 387: 179-181

27. Aguilar-Bryan L, Clement JP IV, Gonzalez G et al. (1998) Toward understanding the assembly and structure of KATP channels. Physiol Rev 78: 227-245

28. Gribble FM, Ashfield R, Ämmälä C et al. (1997) Properties of cloned ATP-sensitive K-currents expressed in Xenopus oocytes. J Physiol 498: 87-98

29. Wahl P, Anker C, Traynelis SF et al. (1998). Antagonist properties of a phosphonoisoxazole amino acid at gluamate R1-4 (R,S)-2-amino-3(3-hydroxy-5-methyl-4-isoxazolyl)proprionic acid receptor subtypes. Mol Pharmacol 53: 590-596

30. Gribble FM, Tucker SJ, Ashcroft FM (1997) The interaction of nucleotides with the tolbutamide block of cloned ATP-sensitive $\mathrm{K}+$ channel currents expressed in Xenopus oocytes: a reinterpretation. J Physiol 504: 35-45

31. Trapp S, Ashcroft FM (2000) Direct interaction of Naazide with the $\mathrm{K}_{\mathrm{ATP}}$ channel. $\mathrm{Br} \mathrm{J}$ Pharmacol 131: 1105-1112

32. Ashfield R, Gribble FM, Ashcroft SJH, Ashcroft FM (1999). Identification of the high-affinity tolbutamide site on the SUR1 subunit of the K(ATP) channel. Diabetes 48: 1341-1347
33. Zünckler BJ, Lins S, Ohno-Shosaku T et al. (1988) Cytosolic ADP enhances the sensitivity of tolbutamide of ATPdependent $\mathrm{K}^{+}$channels from pancreatic beta-cells. FEBS Lett 239: 241-244

34. Schwanstecher C, Dickel C, Panten U (1992) Cytosolic nucleotides enhance the tolbutamide sensitivity of the ATPdependent K-channel in mouse pancreatic beta-cells by their combined actions at inhibitory and stimulatory sites. Mol Pharmacol 41: 480-486

35. Fuhlendorff J, Rorsman P, Kofod H et al. (1998) Stimulation of insulin release by repaglinide and glibenclamide involves both common and distinct processes. Diabetes 47: 345-351

36. Zünckler BJ, Lenzen S, Männer K et al. (1988) Concentration-dependent effects of tolbutamide, meglitinide, glipizide, glibenclamide and diazoxide on ATP-regulated $\mathrm{K}^{+}$currents in pancreatic B-cells. Naunyn Schmiedebergs Arch Pharmacol 337: 225-230

37. Schwanstecher M, Schwanstecher C, Dickel C et al. (1994) Location of the sulphonylurea receptor at the cytoplasmic face of the beta-cell membrane. Br J Pharmacol 113: 903-911

38. Lee K, Ozanne SE, Rowe ICM et al. (1994) The effects on trypsin of ATP-regulated potassium channel properties and sulphonylurea receptors in the CRI-G1 insulin secreting cell line. Mol Pharmacol 45: 176-185

39. Jijakli H, Ulusoy S, Malaisse WJ (1996) Dissociation between the potency and reversibility of the insulintropic action of two meglitinide derivatives. Pharmacol Res 34: 105-108

40. Damsbo P, Marbury TC, Hatorp V et al. (1999) Flexible prandial glucose regulation with repaglinide in patients with Type 2 diabetes. Diab Res Clin Pract. 45: 31-39

41. Kikuchi M (1996) Modulation of insulin secretion in noninsulin-dependent diabetes mellitus by two novel oral hypoglycaemic agents NN623 and A4166. Diabet Med 9 suppl 6:S151-S155

42. Venkatesh N, Lamp ST, Weiss JN (1991) Sulfonylureas, ATP-sensitive $\mathrm{K}^{+}$channels and cellular $\mathrm{K}^{+}$loss during hypoxia, ischemia and metabolic inhibition in mammalian ventricle. Circ Res 69: 623-637

43. Hu S, Wang S, Dunning BE (1999) Tissue selectivity of antidiabetic agent nateglinide: study on cardiovascular and beta-cell K(ATP) channels. J Pharmacol Exp Ther 291: $1372-1379$

44. Jovanovic L, Dailey G $3^{\text {rd }}$, Huang WC et al. (2000). Repaglinide in Type II diabetes: a 24-week, fixed-dose efficacy and safety study. J Clin Pharmacol. 40(1):49-57

45. UKPDS (1998) Intensive blood-glucose control with sulphonylureas or insulin compared with conventional treatment and risk of complications in patients with type-2 diabetes (UKPDS 33). Lancet 352: 837-853

46. Davis TME, Parsons RW, Broadhurst RJ et al. (1998) Arrhythmia and mortality after myocardial infarction in diabetic patients. Relationship to diabetes treatment. Diabetes Care 21: 637-640

47. Meinert CL, Knatterud GL, Prout TE et al. (1970) A study of the effects of hypoglycemic agents on vascular complications in patients with adult-onset diabetes. II. Mortality results. Diabetes 19: 789-830 